\title{
Low-dose LNG-IUS as Therapy for Endometrial Hyperplasia. A Prospective Cohort Pilot Study
}

\author{
ELISE THORESEN SLETTEN ${ }^{1,2,3}$, MARIT ARNES ${ }^{2}$, ANNE BEATE VEREIDE ${ }^{1,3}$ and ANNE ØRBO $^{2,4}$ \\ ${ }^{1}$ Department of Gynecologic Oncology, Clinic for Surgery, Cancer and Women's Diseases, \\ University Hospital of North Norway, Troms $\phi$, Norway; \\ ${ }^{2}$ Research Group for Gynecologic Oncology, Department of Medical Biology (IMB), \\ Faculty of Health Sciences, University of Troms $\phi$, Troms $\phi$, Norway; \\ ${ }^{3}$ Department of Clinical Medicine (IKM), Faculty of Health Sciences, University of Troms $\phi$, Troms $\phi$, Norway; \\ ${ }^{4}$ Department of Clinical Pathology, University Hospital of Troms $\phi$, Troms $\phi$, Norway
}

\begin{abstract}
Background/Aim: Progestin therapy has been accepted as therapy for low- and medium-risk endometrial hyperplasia. The aim of this study was to investigate the efficacy of the low-dose levonorgestrel-impregnated intrauterine system (LNG-IUS) $13.5 \mathrm{mg}$ (Jaydess ${ }^{\circledR}$, Bayer Pharmaceuticals, Berlin, Germany) as therapy for endometrial hyperplasia. Patients and Methods: A total of 21 women with histologically-verified endometrial hyperplasia were prospectively treated with LNG-IUS Jaydess. Therapy duration was 6 months $(n=16)$ or 3-6 weeks $(n=5)$ depending on individual risk (low-and mediumrisk versus high-risk) for co-existent or future endometrial carcinoma. Paired endometrial biopsies were sampled prior to and after therapy and classified according to the WHO94 classification system and D-score. Results: All women with low- and medium risk endometrial hyperplasia had-therapy response. In the group of women with high-risk endometrial hyperplasia only $40 \%$ (two out of five) obtained a therapy response. Conclusion: Low-dose LNG-IUS Jaydess was proven to be an excellent therapy option for low- and medium-risk endometrial hyperplasia. For patients with high-risk endometrial hyperplasia hysterectomy or LNG-IUS therapy under close surveillance is advised.
\end{abstract}

Endometrial carcinoma (EC) is presently the most frequent

This article is freely accessible online.

Correspondence to: Professor Anne Ørbo, Research Group for Gynecologic Oncology, Department of Medical Biology, Faculty of Health Sciences, University of Troms $\varnothing$, N-9037 Troms $\varnothing$, Norway. Tel: +47 77627220, Fax: +47 77627204,e-mail: anne.orbo@uit.no

Key Words: Endometrial hyperplasia, LNG-IUS, low-dose progestin therapy. genital malignancy in women, showing a constant rise all over the Western world $(1,2)$. Endometrial hyperplasia, the preliminary stage of EC, undergoes malignant transformation in up to $29 \%$ of cases if left untreated (3). Women with atypical endometrial hyperplasia $(\mathrm{AH})$, have been proven to have the highest risk of co-existent or future EC, have routinely been treated by hysterectomy (3-6). In contrast, conservative management with progestin therapy has been used in clinical practice for women with non-atypical endometrial hyperplasia (low- and medium risk), although consensus regarding optimal progestin agent, dose and therapy duration has never been established.

During the recent decades the levonorgestrel-impregnated intrauterine system (LNG-IUS) has been introduced as an alternative to oral therapy for endometrial hyperplasia and cohort studies as well as case reports have shown promising results (7-12). The endometrial mucosal progestin concentration observed in LNG-IUS $63 \mathrm{mg}$ users has been measured hundred-fold higher than in oral progestin users (13). A recent randomized national multicentre study comparing the high-dose LNG-IUS 52 mg (Mirena ${ }^{\circledR}$, Bayer Pharmaceuticals, Berlin, Germany) with oral progestin as therapy for low- and medium risk endometrial hyperplasia, reported $100 \%$ therapy response for LNG-IUS Mirena after 6 months therapy duration (14). Lower response rates were found for cyclic (67\%) and continuous (96\%) oral progestin (14).

In selected cases progestin therapy has also been recommended for women with $\mathrm{AH}$ (high-risk). It has also been considered as an option for women desiring fertility preservation and for non-ideal surgical candidates. Recent results have demonstrated resolution of high-risk endometrial hyperplasia in 66\%-85.6\% after use of progestin therapy, intrauterine therapy being superior to oral administration (1517). However, the ideal mucosal concentration of progestin for reversal of low- and medium versus high-risk endometrial hyperplasia is still unknown. 
The low-dose LNG-IUS (Jaydess ${ }^{\circledR}$, Bayer Pharmaceuticals, Berlin, Germany), recommended for contraception, has a total content of $13.5 \mathrm{mg}$ levonorgestrel and releases an average of 6 $\mu \mathrm{g} / 24$ hours over 3 years $(18,19)$. By comparison, the average release rate for LNG-IUS Mirena is $14 \mu \mathrm{g} / 24$ hours over 5 years. The low progestin dose provided by LNG-IUS Jaydess is beneficial to reduce systemic side effects to a minimum. In addition, LNG-IUS Jaydess is designed with a smaller T-frame and thinner insertion tube compared to LNG-IUS Mirena, an advantage for young, nulliparous women and elderly women with stenotic cervical channel. In the present prospective cohort study the efficacy of LNG-IUS Jaydess as therapy in 16 women with low- and medium risk endometrial hyperplasia after 6 months of therapy was investigated. The effect of LNGIUS Jaydess in five women with high-risk endometrial hyperplasia and shorter therapy duration is also reported.

\section{Patients and Methods}

Patients. In the current study 23 women with histologically verified endometrial hyperplasia were enrolled from five different gynecological outpatient clinics in northern Norway between December 2015 and July 2017. The index endometrial biopsies had been obtained by Pipelle (Pipelle ${ }^{\circledR}$, Laboratoire CCD, Paris, France) $(n=16), D \& C$ (dilatation and curettage) $(n=4)$ or hysteroscopic endometrial resection $(n=3)$ due to menometrorrhagia $(n=14)$, menorrhagia $(n=5)$ or postmenopausal vaginal bleedings $(n=4)$. Two women reported ongoing use of hormonal replacement therapy (HRT). Endometrial thickness evaluated by transvaginal ultrasound (TVUS) varied between one and $18 \mathrm{~mm}$. Index biopsies were classified according to WHO94 classification and D-score. D-score category ( $\mathrm{D}$-score $\geq 0$ versus $\mathrm{D}$-score $<0$ ) were decisive for therapy group (therapy group A and therapy group B). Patients in therapy group A, estimated to have low- and medium risk of co-existent or future EC, were treated conservatively with LNG-IUS Jaydess for 6 months. Patients in therapy group B were scheduled for hysterectomy due to high risk of co-existent or future EC and underwent therapy with LNG-IUS Jaydess while waiting for surgery (3-6 weeks). Control biopsies after six months of therapy were sampled by Pipelle in therapy group A, whereas in therapy group B the hysterectomy specimen was sent to histopathological evaluation after surgery.

Endometrial biopsies. The endometrial biopsy and hysterectomy specimens were received at the Department of Pathology at the University Hospital of North Norway for routine assessment. The samples were fixed in buffered formaldehyde, embedded in paraffin and further processed in the laboratory before standard histological sections were made. Diagnostic assessment of WHO94 classification by light microscopy was performed by a trained gynecologic pathologist (AO) and one additional routine pathologist, both of whom were blinded to each other's diagnosis. Agreement after discordant results was always obtained after discussion at a two-headed microscope. The index biopsies were classified into one of three groups: simple hyperplasia ( $\mathrm{SH})$, complex hyperplasia $(\mathrm{CH})$ or atypical hyperplasia $(\mathrm{AH})$ according to the WHO94 classification, which was still considered the gold standard for evaluation of endometrial hyperplasia when the study was planned and formally approved $(3,20)$ Normalized histology in the control biopsies after therapy was defined as ordinary proliferative endometrium or endometrium with the progestin effect (20). All information from the WHO94 classification of the index and control biopsies were registered and maintained in a separate database and subsequently supplemented by information from hospital records.

$D$-score. After microscopical diagnostics and consensus according to WHO94 classification, the morphometric image analyses algorithm D-score was performed to improve stratification of risk groups. The D-score method has proven superior to WHO94 classification in the prediction of cancer outcome (21-24). Women with D-score $0-1$ or $>1$ are considered to have medium- and low risk of malignant progression, respectively, and conservative therapy is accepted. Women with $\mathrm{D}$-score $<0$ are considered to have high risk of co-existent or future EC (24). The current clinical recommendation for these patients in our health region is hysterectomy. The D-score analyses were performed by two trained engineers. In the original computerized morphometric analysis on endometrial hyperplasia, a total of 10 nuclear features and 12 architectural features were analyzed using a linear stepwise regression analysis and discriminant analysis. Three of these quantitative features were selected as having significant independent prognostic value and were combined into the formula called Dscore, as follows: $D$-score $=0.6229+0.0439 \times($ volume percentage stroma) $-3.9934 \times$ Ln (standard deviation shortest nuclear axis) $0.1592 \times$ (outer surface density glands), where Ln stands for natural logarithm. The measurements were performed with a Q-PRODIT image analysis system (version 6.1; Leica, Cambridge, UK). The method describing the performance of the D-score method has been described in detail in former studies $(21,23,25)$.

Ethical approval. The study was approved by the Regional Committees for Medical and Health Research Ethics (2015/381) and by the Norwegian Medicines Agency (EUDRACT nr 2015-00061217). Study protocol is available at EU Clinical Trials Register. Written informed consent was mandatory. Insurance for coverage of pharmaceutical injuries was signed for all study participants.

\section{Results}

Patients. Among the 23 women prospectively recruited to the study, 18 underwent therapy with LNG-IUS Jaydess for 6 months (therapy group A) while the remaining five women had LNG-IUS Jaydess inserted for 3-6 weeks while pending for hysterectomy (therapy group B). Two patients in therapy group A withdrew from the study after 3 and 11 weeks respectively, due to intolerable vaginal bleeding and consequently decided to remove the LNG-IUS (Figure 1). Clinical and demographic characteristics of the study cohort completing the study $(n=21)$ are summarized in Table I. Median age at study inclusion was 47.0 years (range $=28-63$ years), $28.6 \%$ were in reproductive age $<45$ years, of whom two were nulliparous. The majority of the patients were overweight as $66.6 \%$ had $\mathrm{BMI} \geq 25$. Median BMI in the study population was 26.12 (range $=19.47-46.57 \mathrm{BMI}$ ). Table II shows the distribution of histological WHO94 diagnosis and D-score categories in the index biopsies for both therapy 


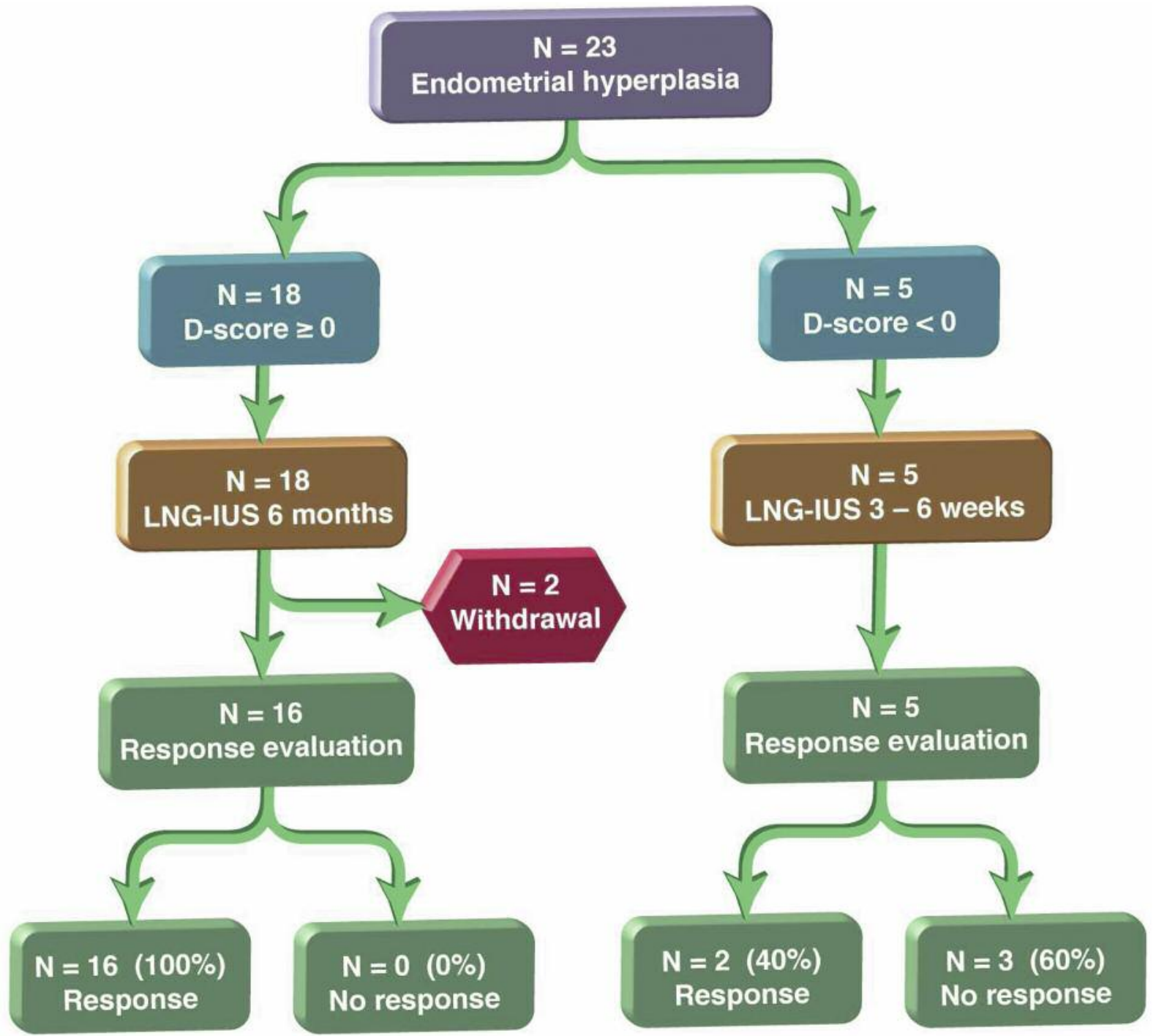

Figure 1. Flow chart showing study inclusion, therapy groups, withdrawal and therapy response. Therapy response is defined as complete clearance of hyperplastic glands.

groups. Therapy group A (D-score $\geq 0)$ is dominated by $\mathrm{SH}$ and $\mathrm{CH}$ while therapy group $\mathrm{B}(\mathrm{D}$-score $<0)$ consists of $\mathrm{CH}$ and $\mathrm{AH}$.

Response to therapy. In therapy group A all women $(\mathrm{n}=16)$ obtained complete response after 6 months treatment time. Control biopsies displayed inactive or sparse atrophic endometrial glands as well as pseudo-decidualised endometrial stroma (Figure 2A and B). Of the two women who interrupted the study, one was hysterectomised and the other had an additional endometrial biopsy. The histological investigation revealed complete therapy response for both. The LNG-IUS was generally well-tolerated by the study participants. In therapy group B two out of five women (40\%) responded to therapy. Among the two women that responded, one had WHO94 diagnosis of $\mathrm{CH}$ and D-score -0.0 in index biopsy. The other had a WHO94 diagnosis of $\mathrm{CH}$ and D-score -0.2 in index biopsy (Figure 2C and D). The three women lacking therapy response all had WHO94 diagnosis of $\mathrm{AH}$ and Dscore values of $-0.3,-0.7$ and -2.1 respectively, in their index biopsies. For the woman with D-score -2.1 in index biopsy, small foci of highly differentiated EC limited to the mucosal membrane (Figo stage 1a) were diagnosed in the hysterectomy specimen (Figure 2E and F). Association between clinical characteristics and therapy response, independent of therapy group, are summarized in Table III. 
Table I. Clinical and demographic characteristics of study cohort, $n=21$.

\begin{tabular}{|c|c|c|}
\hline & $\mathrm{n}$ & $(\%)$ \\
\hline \multicolumn{3}{|l|}{ Age (years) } \\
\hline$<45$ & 6 & 28.6 \\
\hline $45-55$ & 12 & 57.1 \\
\hline$>55$ & 3 & 14.3 \\
\hline \multicolumn{3}{|l|}{ BMI $\left(\mathrm{kg} / \mathrm{m}^{2}\right)$} \\
\hline Normal Weight (18.5-24.9) & 7 & 33.3 \\
\hline Overweight (25-29.9) & 10 & 47.6 \\
\hline Obese $(\geq 30)$ & 4 & 19.0 \\
\hline \multicolumn{3}{|l|}{ Waist $(\mathrm{cm})$} \\
\hline$<95$ & 14 & 66.7 \\
\hline $95-119$ & 6 & 28.6 \\
\hline$\geq 120$ & 1 & 4.8 \\
\hline \multicolumn{3}{|l|}{ Estradiol level (nmol/l) } \\
\hline$<0.12$ & 3 & 14.3 \\
\hline $0.12-0.26$ & 8 & 38.1 \\
\hline$\geq 0.27$ & 10 & 47.6 \\
\hline \multicolumn{3}{|l|}{ Menopausal status* } \\
\hline Premenopausal & 12 & 57.1 \\
\hline Perimenopausal & 5 & 23.8 \\
\hline Postmenopausal & 4 & 19.0 \\
\hline \multicolumn{3}{|l|}{ Vaginal bleeding } \\
\hline Menometrorrhagia & 14 & 66.7 \\
\hline Menorrhagia & 3 & 14.3 \\
\hline Postmenopausal bleeding & 4 & 19.0 \\
\hline \multicolumn{3}{|l|}{ Parity } \\
\hline 0 & 3 & 14.3 \\
\hline $1-2$ & 13 & 61.9 \\
\hline $3-4$ & 5 & 23.8 \\
\hline$>4$ & 0 & 0 \\
\hline \multicolumn{3}{|l|}{ Method of diagnosis } \\
\hline Pipelle & 15 & 71.4 \\
\hline $\mathrm{D} \& \mathrm{C}$ & 4 & 19.0 \\
\hline Hysteroscopic resection & 2 & 9.5 \\
\hline \multicolumn{3}{|l|}{ WHO94 diagnosis } \\
\hline SH & 5 & 23.8 \\
\hline $\mathrm{CH}$ & 12 & 57.1 \\
\hline $\mathrm{AH}$ & 4 & 19.0 \\
\hline \multicolumn{3}{|l|}{ D-score category } \\
\hline$<0$ & 5 & 23.8 \\
\hline$\geq 0$ & 16 & 76.2 \\
\hline
\end{tabular}

*Menopausal status was defined according to s-estradiol (nmol/l) and sFSH (IU/l). Premenopausal, estradiol $\geq 0.12$ FSH $\leq 30$; Perimenopausal, estradiol $\geq 0.12$ FSH $>30$; Postmenopausal, estradiol $<0.12$ FSH $>20$. BMI: Body Mass Index; D\&C: dilatation and curettage; SH: Simple hyperplasia; $\mathrm{CH}$ : complex hyperplasia; $\mathrm{AH}$ : atypical hyperplasia.

Adverse events. Vaginal bleeding disturbances assumed related to study medicine was reported in 9 out of the 21 women. Seven had vaginal bleeding $\geq 10$ days/month and two had vaginal bleeding $<10$ days/month. Except for the two women who withdrew from the study due to vaginal bleeding, the remaining patients had gradual decrease in vaginal bleeding after 3 months and acceptable bleeding after 6 months of therapy.
Table II. Distribution of histological WHO94 diagnosis(3) and Dscore(21) categories in index biopsies. Patients with $D$-score $\geq 0$ were included in therapy group $A$ and patients with $D$-score $<0$ were included in therapy group $B$.

\begin{tabular}{lccr}
\hline $\begin{array}{l}\text { WHO94 diagnosis/ } \\
\text { therapy group }\end{array}$ & $\begin{array}{c}\mathrm{n}=16 \\
\text { D-score } \geq 0\end{array}$ & $\begin{array}{c}\mathrm{n}=5 \\
\text { D-score }<0\end{array}$ & Total \\
\hline SH & 5 & 0 & 5 \\
CH & 10 & 2 & 12 \\
AH & 1 & 3 & 4 \\
& 16 & 5 & 21 \\
\hline
\end{tabular}

SH: Simple hyperplasia; $\mathrm{CH}$ : complex hyperplasia; AH: atypical hyperplasia.

\section{Discussion}

This current cohort pilot study is, to our knowledge, the first ever to investigate prospective low-dose LNG-IUS $13.5 \mathrm{mg}$, releasing average $6 \mu \mathrm{g}$ levonorgestrel/24 hours, as therapy for endometrial hyperplasia. The $100 \%$ response rate demonstrated for patients with low- and medium risk endometrial hyperplasia after 6 months therapy in the present study are in concordance with previous findings comparing the efficacy of various progestin therapy regimens (14). The exact mucosal concentration of levonorgestrel after LNG-IUS Jaydess use is unknown, however, intrauterine therapy has demonstrated to give a multiply higher concentration of progestin in the endometrial mucosa compared to oral administration (13). Thus, our present results may contribute to establish LNG-IUS Jaydess as a sufficient therapy option for women with low- and medium risk endometrial hyperplasia.

In contrast, only two out of five women with high-risk endometrial hyperplasia obtained therapy response, clearly a lower response rate than previously reported (26). A systematic review found a pooled regression rate of $90 \%$ for AH treated with LNG-IUS 14/20 $\mu \mathrm{g}$ levonorgestrel/24 hours and a dose-dependent increase in response rate when oral progestin was compared to LNG-IUS (26). Mean time taken to achieve complete response for patients with $\mathrm{AH}$ and early EC on different progestin therapy regimens was 5.9 months (range $=1-12$ months) in a meta-analysis (27). Whether the progestin dose delivered to the endometrium by the LNG-IUS Jaydess is too low to overcome high-risk endometrial hyperplasia or if the short duration of therapy (3-6 weeks) is explanatory for the low response rate in women with high-risk endometrial hyperplasia in our study remains to be clarified.

Several studies have evaluated clinical characteristics as predictors of therapy response in patients with endometrial hyperplasia (28-30). Brownfoot and co-workers reported higher regression rates $(76 \%)$ for conservatively treated premenopausal women with AH than for postmenopausal 

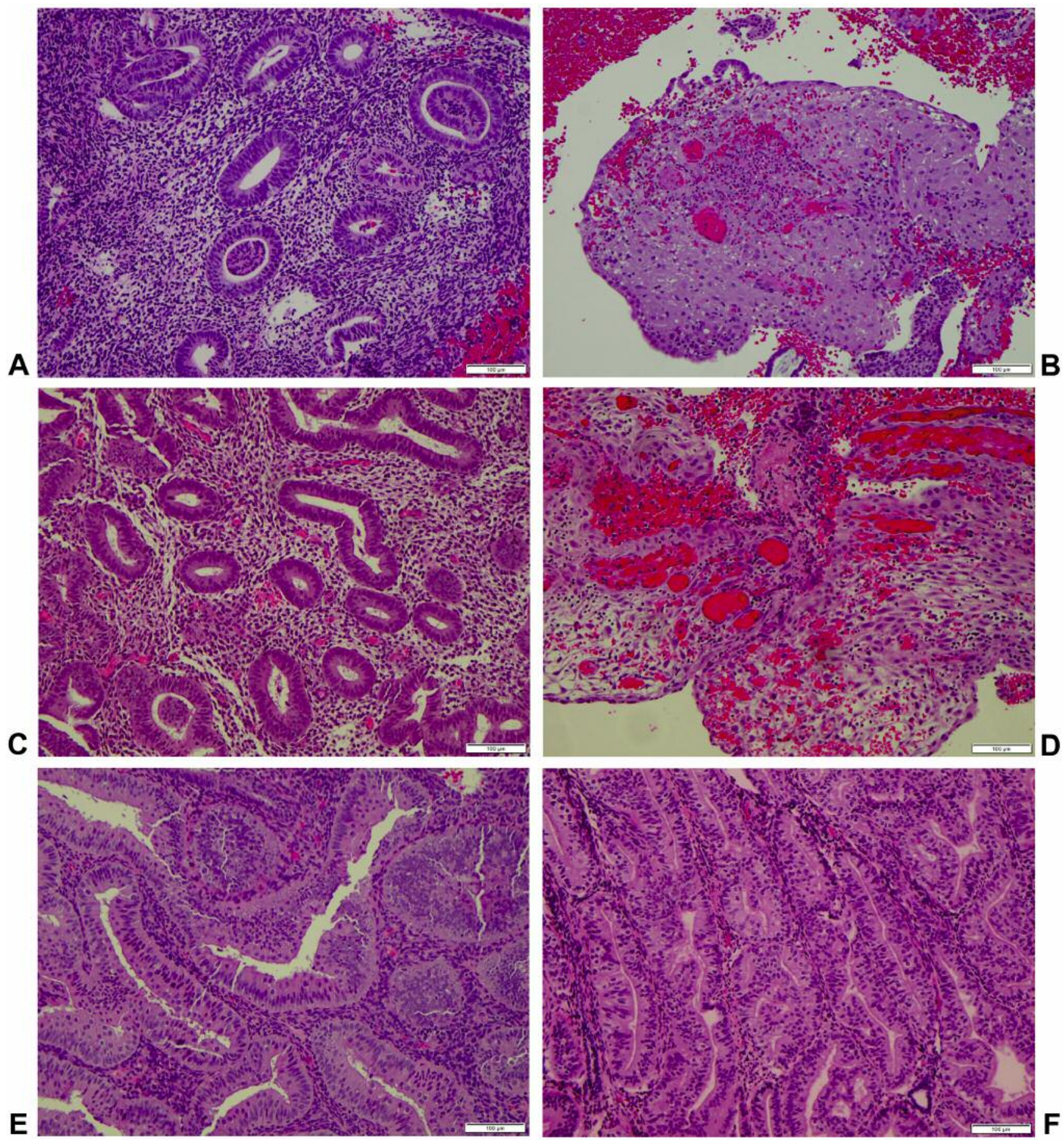

Figure 2. The panel demonstrates microphotographs from histological specimens of endometrial biopsies, taken before and after 6 months of therapy with LNG-IUS Jaydess (stained with hematoxylin and eosin, 20x magnifications. SH: Simple hyperplasia; CH: complex hyperplasia: AH: atypical hyperplasia, EC: endometrial carcinoma). Image represents the index biopsy from a woman in therapy group A showing an area with irregular glands separated by abundant stroma. The WHO94 diagnosis was SH and D-score 1.8 (A). The control biopsy taken after six months of therapy is dominated by pseudo-decidualised stroma and extensive glandular atrophy $(B)$. Image represents the index biopsy from a woman in therapy group $B$ showing tightly packed glands. The WHO94 diagnosis was $\mathrm{CH}$ and D-score -0.2 (C). The biopsy taken after 5 weeks of therapy shows therapy response dominated by pseudo-decidualised stroma and glandular atrophy $(D)$. Image from the index biopsy in another woman in therapy group $B$ showing tightly packed irregular glands with cellular atypia and small amounts of stroma encompassing each gland. The biopsy was characterized as AH and D-score -2.1 (E). After 5 weeks of therapy several foci of highly differentiated EC limited to the endometrial mucosa were found in the hysterectomy specimen $(F)$. 
Table III. Association between clinical characteristics and therapy response, $n=21$.

\begin{tabular}{lcc}
\hline $\begin{array}{l}\text { Clinical characteristics/ } \\
\text { therapy response }\end{array}$ & $\begin{array}{c}\mathrm{n}=18 \\
\text { Response }\end{array}$ & $\begin{array}{c}\mathrm{n}=3 \\
\text { No response }\end{array}$ \\
\hline Age (years), mean (range) & $46,3(28-57)$ & $56,0(50-63)$ \\
BMI (kg/m $\left.{ }^{2}\right)$, mean (range) & $26,59(19.47-40.56)$ & $33,13(25.82-46.57)$ \\
Waist $(\mathrm{cm})$, mean (range) & $90,4(69-117)$ & $107,3(89-133)$ \\
Parity, mean (range) & $1,89(0-4)$ & $2,0(1-3)$ \\
Estradiol level (nmol/1), & & \\
mean (range) & $0,55(0.10-2.24)$ & $0,19(0.14-0.25)$ \\
Menopausal status & 12 & 0 \\
Premenopausal & 3 & 2 \\
Perimenopausal & 3 & 1 \\
Postmenopausal & & 0 \\
WHO94 diagnosis & 5 & 0 \\
SH & 12 & 3 \\
CH & 1 & 3 \\
AH & 2 & 0 \\
D-score & 16 & \\
$<0$ & & \\
$\geq 0$ & &
\end{tabular}

BMI: Body Mass Index; SH: simple hyperplasia; $\mathrm{CH}$ : complex hyperplasia; $\mathrm{AH}$ : atypical hyperplasia.

women (21\%) (28). Progression to EC was also significantly higher in the group of postmenopausal women with AH (28). Obesity has been associated with higher risk of therapy failure for both non-atypical hyperplasia and $\mathrm{AH}(29,30)$. Penner and collaborators also showed that time to resolution of AH and early EC in morbidly obese patients (BMI $\geq 35$ ) was prolonged (29). Higher mean BMI level and higher mean age in patients without therapy response was found compared to responders, but the patient group is too small for drawing reliable conclusions.

In our recent RCT comparing high-dose LNG-IUS Mirena with oral progestin we demonstrated that more than $40 \%$ of patients with low- and medium risk endometrial hyperplasia relapsed within two years after therapy withdrawal independent of therapy regime (31). A threefold higher risk of relapse of endometrial hyperplasia after successful LNG-IUS therapy for obese women (BMI $>35 \mathrm{~kg} / \mathrm{m}^{2}$ ) with $\mathrm{CH}$ has been demonstrated (30). In the current study, participants reported satisfactory tolerance for LNG-IUS Jaydess and none had systemic sideeffects during the 6-month therapy period. Correspondingly, long-term use of LNG-IUS Jaydess might be recommended to prevent relapse of endometrial hyperplasia, and also as prophylactic use of LNG-IUS to prevent endometrial hyperplasia and EC development, particularly in obese women (32).

This study has important limitations inherent to the small study population in therapy group B and the short duration of therapy for these women. Surgery with hysterectomy was recommended after 3-6 weeks for patients with high-risk endometrial hyperplasia in accordance to current guidelines in our health region. As the low-dose LNG-IUS has never before been explored as therapy for endometrial hyperplasia we preferred not to deviate from recommendations for ethical reasons, but for future research larger patient series with longer therapy duration are mandatory to gain trustable information.

The current pilot study has demonstrated that the low-dose LNG-IUS Jaydess proved to be an excellent therapy option for low- and medium-risk endometrial hyperplasia. However, close follow-up with periodic endometrial resampling is mandatory if LNG-IUS Jaydess is considered as therapy for high-risk endometrial hyperplasia.

\section{Acknowledgements}

The Authors would like to thank participating gynecological outpatient clinics in northern Norway, Lena M.M. Lyså, BSc, and Bjørn T.G. Moe, MSc, for skilled image analyses performed on endometrial specimens and Roy Andre Lyså for figure artwork.

\section{References}

1 Horn LC, Schnurrbusch U, Bilek K, Hentschel B and Einenkel $\mathrm{J}$ : Risk of progression in complex and atypical endometrial hyperplasia: clinicopathologic analysis in cases with and without progestogen treatment. Int J Gynecol Cancer 14: 348-353, 2004.

2 Okuda T, Sekizawa A, Purwosunu Y, Nagatsuka M, Morioka M, Hayashi M and Okai T: Genetics of endometrial cancers. Obstet Gynecol Int, 2010. doi: 10.1155/2010/984013. [Epub ahead of print]

3 Kurman RJ, Kaminski PF and Norris HJ: The behavior of endometrial hyperplasia. A long-term study of "untreated" hyperplasia in 170 patients. Cancer 56: 403-412, 1985.

4 Clark TJ, Neelakantan D and Gupta JK: The management of endometrial hyperplasia: an evaluation of current practice. Eur J Obstet Gynecol Reprod Biol 125: 259-264, 2006.

5 Orbo A, Kaino T, Arnes M, Larsen K, Pettersen I and Moe B: Prognostic markers for coexistent carcinoma in high-risk endometrial hyperplasia with negative D-score: significance of morphometry, hormone receptors and apoptosis for outcome prediction. Acta Obstet Gynecol Scand 88: 1234-1242, 2009.

6 Trimble CL, Kauderer J, Zaino R, Silverberg S, Lim PC, Burke JJ, 2nd, Alberts D and Curtin J: Concurrent endometrial carcinoma in women with a biopsy diagnosis of atypical endometrial hyperplasia: a Gynecologic Oncology Group study. Cancer 106: 812-819, 2006.

7 Perino A, Quartararo P, Catinella E, Genova G and Cittadini E: Treatment of endometrial hyperplasia with levonorgestrel releasing intrauterine devices. Acta Eur Fertil 18: 137-140, 1987.

8 Scarselli G, Tantini C, Colafranceschi M, Taddei GL, Bargelli $\mathrm{G}$, Venturini $\mathrm{N}$ and Branconi F: Levo-norgestrel-nova-T and precancerous lesions of the endometrium. Eur J Gynaecol Oncol 9: 284-286, 1988.

9 Vereide AB, Arnes M, Straume B, Maltau JM and Orbo A: Nuclear morphometric changes and therapy monitoring in patients with endometrial hyperplasia: a study comparing effects of intrauterine levonorgestrel and systemic medroxyprogesterone. Gynecol Oncol 91: 526-533, 2003. 
10 Wildemeersch D, Janssens D, Pylyser K, De Wever N, Verbeeck G, Dhont M and Tjalma W: Management of patients with nonatypical and atypical endometrial hyperplasia with a levonorgestrel-releasing intrauterine system: long-term followup. Maturitas 57: 210-213, 2007.

11 Varma R, Soneja H, Bhatia K, Ganesan R, Rollason T, Clark TJ and Gupta JK: The effectiveness of a levonorgestrel-releasing intrauterine system (LNG-IUS) in the treatment of endometrial hyperplasia - a long-term follow-up study. Eur J Obstet Gynecol Reprod Biol 139: 169-175, 2008.

12 Buttini MJ, Jordan SJ and Webb PM: The effect of the levonorgestrel releasing intrauterine system on endometrial hyperplasia: an Australian study and systematic review. Aust N Z J Obstet Gynaecol 49: 316-322, 2009.

13 Nilsson CG, Haukkamaa M, Vierola $\mathrm{H}$ and Luukkainen T: Tissue concentrations of levonorgestrel in women using a levonorgestrel-releasing IUD. Clin Endocrinol 17: 529-536, 1982.

14 Orbo A, Vereide A, Arnes M, Pettersen I, and Straume B: Levonorgestrel-impregnated intrauterine device as treatment for endometrial hyperplasia: a national multicentre randomised trial BJOG 121: 477-486, 2014.

15 Gunderson CC, Fader AN, Carson KA and Bristow RE: Oncologic and reproductive outcomes with progestin therapy in women with endometrial hyperplasia and grade 1 adenocarcinoma: a systematic review. Gynecol Oncol 125: 477-482, 2012.

16 Gallos ID, Yap J, Rajkhowa M, Luesley DM, Coomarasamy A and Gupta JK: Regression, relapse, and live birth rates with fertility-sparing therapy for endometrial cancer and atypical complex endometrial hyperplasia: a systematic review and metaanalysis. Am J Obstet Gynecol 207: 266.e1-12, 2012.

17 Yuk JS, Song JY, Lee JH, Park WI, Ahn HS and Kim HJ: Levonorgestrel-Releasing Intrauterine Systems Versus Oral Cyclic Medroxyprogesterone Acetate in Endometrial Hyperplasia Therapy: A Meta-Analysis. Ann Surg Oncol 24: 1322-1329, 2017.

18 Gemzell-Danielsson K, Schellschmidt I and Apter D: A randomized, phase II study describing the efficacy, bleeding profile, and safety of two low-dose levonorgestrel-releasing intrauterine contraceptive systems and Mirena. Fertil Steril 97: 616-622.e1-e3, 2012.

19 Fan G, Kang S, Ren M, Weisberg E, Lukkari-Lax E, Roth K and Shin S: A single-arm phase III study exploring the efficacy and safety of LNG-IUS 8, a low-dose levonorgestrel intrauterine contraceptive system (total content $13.5 \mathrm{mg}$ ), in an Asia-Pacific population. Contraception 95: 371-377, 2017.

20 Gallos ID, Krishan P, Shehmar M, Ganesan R and Gupta JK: Relapse of endometrial hyperplasia after conservative treatment: a cohort study with long-term follow-up. Hum Reprod 28: 12311236, 2013.

21 Baak JP, Nauta JJ, Wisse-Brekelmans EC and Bezemer PD: Architectural and nuclear morphometrical features together are more important prognosticators in endometrial hyperplasias than nuclear morphometrical features alone. J Pathol 154: 335-341, 1988.

22 Mutter GL, Baak JP, Crum CP, Richart RM, Ferenczy A and Faquin WC: Endometrial precancer diagnosis by histopathology, clonal analysis, and computerized morphometry. J Pathol 190 : 462-469, 2000 .
23 Orbo A, Baak JP, Kleivan I, Lysne S, Prytz PS, Broeckaert MA, Slappendel A and Tichelaar HJ: Computerised morphometrical analysis in endometrial hyperplasia for the prediction of cancer development. A long-term retrospective study from northern Norway. J Clin Pathol 53: 697-703, 2000.

24 Baak JP, Mutter GL, Robboy S, van Diest PJ, Uyterlinde AM, Orbo A, Palazzo J, Fiane B, Lovslett K, Burger C, Voorhorst F and Verheijen RH: The molecular genetics and morphometrybased endometrial intraepithelial neoplasia classification system predicts disease progression in endometrial hyperplasia more accurately than the 1994 World Health Organization classification system. Cancer 103: 2304-2312, 2005.

25 Baak JP, Orbo A, van Diest PJ, Jiwa M, de Bruin P, Broeckaert M, Snijders W, Boodt PJ, Fons G, Burger C, Verheijen RH, Houben PW, The HS and Kenemans P: Prospective multicenter evaluation of the morphometric D-score for prediction of the outcome of endometrial hyperplasias. Am J Surg Pathol 25: 930935, 2001.

26 Gallos ID, Shehmar M, Thangaratinam S, Papapostolou TK, Coomarasamy A and Gupta JK: Oral progestogens vs levonorgestrel-releasing intrauterine system for endometrial hyperplasia: a systematic review and metaanalysis. Am J Obstet Gynecol 203: 547.e1-e10, 2010.

27 Baker J, Obermair A, Gebski V and Janda M: Efficacy of oral or intrauterine device-delivered progestin in patients with complex endometrial hyperplasia with atypia or early endometrial adenocarcinoma: a meta-analysis and systematic review of the literature. Gynecol Oncol 125: 263-270, 2012.

28 Brownfoot FC, Hickey M, Ang WC, Arora V and McNally O: Complex atypical hyperplasia of the endometrium: differences in outcome following conservative management of pre- and postmenopausal women. Reprod Sci 21: 1244-1248, 2014.

29 Penner KR, Dorigo O, Aoyama C, Ostrzega N, Balzer BL, Rao J, Walsh CS, Cass I and Holschneider $\mathrm{CH}$ : Predictors of resolution of complex atypical hyperplasia or grade 1 endometrial adenocarcinoma in premenopausal women treated with progestin therapy. Gynecol Oncol 124: 542-548, 2012.

30 Gallos ID, Ganesan R and Gupta JK: Prediction of regression and relapse of endometrial hyperplasia with conservative therapy. Obstet Gynecol 121: 1165-1171, 2013.

31 Orbo A, Arnes M, Vereide AB and Straume B: Relapse risk of endometrial hyperplasia after treatment with the levonorgestrelimpregnated intrauterine system or oral progestogens. BJOG 123: 1512-1519, 2016.

32 Carlson MJ, Thiel KW, Yang S and Leslie KK: Catch it before it kills: progesterone, obesity, and the prevention of endometrial cancer. Discov Med 14: 215-222, 2012.
Received March 19, 2018

Revised April 4, 2018

Accepted April 10, 2018 